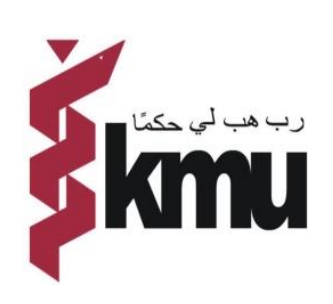

\title{
IIIMI)
}

\section{INFORMATION SHEET}

\section{Effect of Nutritional Supplements on Energy Intake, Appetite, Lipid Profile and Micronutrient Status of Moderate Underweight Children}

We are asking if your child would like to take part in a research project to find the answer to the question; Is high energy nutritional supplement helpful in improving appetite, energy intake and micronutrient status of moderate underweight children and what will be its effect on lipid profile of these children? Before you decide about your child to join in, it's important to understand why the research is being done and what it will involve for your child. Please discuss this with others and ask us any questions you may have. We will be happy to answer them. This research project is part of the higher education of Aqsa Zubair, Fouzia Nawab, Meera Tanveer and Akhlaq Ahmed, M.Phil researchers, Khyber Medical University Peshawar.

Why are we doing this research?

We want to find out the effect of high energy nutrient supplement on appetite, energy intake and lipid profile on of mild to moderate underweight children.

Why your child has been invited to take part?

Your child has been invited to join our study because your child is underweight and fulfill our study criteria.

Does my child have to take part?

No. It is up to you. If you do, a researcher will ask you to sign a form which says that your child is happy to take part. You will be given a copy of this information sheet and your signed form to keep. Your child is free to stop taking part at any time during the study without giving a reason. If you decide to stop, this will not affect the care your child receives.

What will happen if I take part?

After your child agrees to participate, the researcher will ask you;

1. To permit us to look into your child's medical records for information relevant to this study e.g. your child's height and weight.

2. To record your child's 24 hour dietary history

3. To take your child's blood sample.

We will explain how we will collect child's blood sample and provide clear instructions. When the samples are collected, we will bring the samples to the laboratory. 


\section{What are the possible benefits and risks of taking part?}

The supplement provided might help to increase the dietary intake and as a result an increase in weight of the patient. In addition to this it will give me the information about changes in lipid profile due to this supplementation.

\section{Will my child's taking part be kept confidential?}

Yes, no one will know about your participation in this research apart from the researchers of this study. However, we would like to inform your GP about your participation only if you are happy with it.

\section{What will happen to any samples I give?}

We will do some special tests to see the effect of supplements on appetite and changes in the lipid profile and micronutrient status.

\section{How will the information I provide be used?}

We plan to publish the results in scientific journals and other relevant places so that others can read about and learn from the results of the study.

\section{Who is organizing and funding the research?}

The study is part of educational research and is organized by the Khyber Medical University, Peshawar. It has been funded by Khyber Medical University, Pakistan.

\section{Further Information}

If you or your family needs further information, you can always contact us at the following addresses;

- Aqsa Zubair, M.Phil. Scholar, IBMS, Khyber Medical University, Peshawar. Contact no: 03348294688 email; aqsazbr2@gmail.com

- Fouzia Nawab, M.Phil. Scholar, IBMS, Khyber Medical University, Peshawar. Contact no: 03343412121 email; fouzia.nawab20@ gmail.com

- Meera Tanveer, M.Phil. Scholar, IBMS, Khyber Medical University, Peshawar. Contact no: 03349534604 email; meeratanveer1@ @otmail.com

- Akhlaq Ahmed: 03339625130 email: akhlaqahmedbiochem@ gmail.com

Thank you for reading this 